\title{
Impact of bone SPECT-CT imaging on evaluation of lower extremities' abnormalities
}

This article was published in the following Dove Press journal:

Research and Reports in Nuclear Medicine

23 July 2012

Number of times this article has been viewed

\section{Isis Gayed \\ David Wan \\ Charles Beasley \\ Usha Joseph \\ John Awad \\ Susan John}

The University of Texas Health Sciences Center at Houston,

Houston, TX, USA
Correspondence: Isis W Gayed University of Texas-Houston Medical School, Department of Radiology, 643I Fannin, Suite 2.130b, Houston, TX 77030, USA

$\mathrm{Tel}+|7| 37041789$

Fax +I 7I3704 I596

Email isis.w.gayed@uth.tmc.edu
Aim: This study aims to investigate the value of single photon emission computed tomographycomputed tomography (SPECT-CT) imaging as part of bone scans for evaluation of a variety of pathologies of the lower extremities.

Methods: The study included patients who had undergone SPECT-CT imaging as part of a bone scan between February, 2008 and May, 2009. Patients who had multiple bony metastases were excluded. Two expert readers, informed only of the site of pain, independently interpreted planar images, planar plus SPECT images, and Planar plus SPECT-CT images. The interpretations were graded as: Not certain of etiology (NS), Somewhat certain (SC), and Certain (C). Changes or additions to diagnosis and/or location of pathology were graded as (D).

Results: A total of 35 consecutive patients were included, 19 females and 16 males, with an average age of 44 years. There was agreement between the two readers on the site of pathology in 32 out of 35 patients. The degree of certainty for both readers increased significantly with the addition of SPECT-CT. The certainty of diagnosis increased from $26 \%$, using planar images alone, to $44 \%$, with the addition of SPECT, to $74 \%$, with the addition of SPECT-CT, for Reader 1 , and from $40 \%$, to $54 \%$, to $69 \%$, respectively, for Reader 2 . SPECT alone added six $(17 \%)$ new sites of pathology to those identified from planar images, changed the diagnosis for one patient, and added a diagnosis for one other $(6 \%)$. SPECT-CT changed the diagnosis for three patients, and added another diagnosis for one more patient (11\%).

Conclusion: SPECT-CT increased the certainty of location and diagnosis of bony pathology in the lower extremity by at least $30 \%$ across a wide variety of abnormalities.

Keywords: lower extremities, SPECT-CT, bone scan

\section{Introduction}

Bone scans are well-established as a sensitive imaging method for identification of bony abnormalities in different pathologies and in different areas of the skeleton. ${ }^{1}$ Insults to bone, infection, or malignant lesions of bone are usually visualized early in the course of the pathologic process. This allows early detection of fractures, osteomyelitis, or malignant lesions in bones. ${ }^{2-5}$ On the other hand, the specificity of bone scans in identifying the underlying etiology of bony abnormalities is usually lower than their sensitivity. ${ }^{6}$ Correlation of bone scanning with other radiological exams may be required to increase the specificity and accuracy of identification of the etiology of bony lesions. ${ }^{7-10}$ Similarly, other radiologic imaging modalities are usually needed, in conjunction with bone scanning, for evaluation of response to treatment in bony metastases. ${ }^{11-13}$

The value of single photon emission computed tomography-computed tomography (SPECT-CT) for evaluating bone lesions on bone scans has been investigated in different regions of the body and for different indications. ${ }^{14-18}$ SPECT-CT imaging 
has proved helpful in providing more specific diagnosis of certain bony lesions, as well as superior localization of lesions. However, it has not been investigated with a variety of abnormalities that are routinely found at imaging centers. The lower extremities are sites of different complaints and abnormalities, with a variety of etiologies. Adding specificity and certainty regarding the underlying etiology for any bony lesion in the lower extremities is highly desirable, and would eliminate additional radiological exams or tests, potentially lowering the cost of imaging.

The purpose of this study was to evaluate the usefulness of SPECT-CT in identifying bony abnormalities in the lower extremity and to investigate its impact on the performance and accuracy of bone scans.

\section{Materials and method}

The study included consecutive patients, referred to our nuclear medicine outpatients imaging facility for evaluation of lower extremity abnormalities or complaints, who underwent either delayed or three-phase bone scan with SPECT-CT imaging. These bone scans were performed between February 2008 and May 2009. All complaints or indications for the bone scan were included. Patients with evidence of widespread bony metastases in other sites of the bony skeleton were excluded. Bone scans were acquired using a Biograph camera equipped with simultaneous SPECT and 4-slice CT acquisition. The whole-body scan was acquired using both dual heads with a low energy, high resolution collimator $(10 \%$ window around the Tc-99 m peak, $10 \mathrm{~cm}$ per minute speed, and 240 seconds exposure per pixel). The SPECT images were acquired using 360 degrees of arc, 120 frames, 24 seconds per frame, in a $128 \times 128$ matrix. The CT acquisition was performed using helical rotation (pitch: 1.9, interval: $4.42 \mathrm{~mm}$, slices: 90 , voltage: $140 \mathrm{kV}$, current: $2.5 \mathrm{~mA}$, total exposure: 251 seconds) and was reconstructed using a $512 \times 512$ matrix, $1.1 \mathrm{~mm}$ pixel size, and extended field of view.

\section{Image interpretation}

Bone scan images were interpreted independently by two experienced nuclear medicine physicians, with knowledge only of the reason for the bone scan. The reading physicians were blinded to other clinical information and the findings of other imaging modalities. Each interpreting physician first evaluated the planar images, and provided a possible etiology or diagnosis. Subsequently, they evaluated images with the addition of SPECT, and then with the addition of SPECT-CT. The interpretations were graded as: Not certain of etiology (NS), Somewhat certain (SC), or Certain (C), when planar images were interpreted alone, with the addition of SPECT, and with the addition of SPECT-CT. After the addition of SPECT or SPECT-CT, any change to or addition of diagnosis and/or location of lesion that had been based on the initial planar image interpretation was noted. Agreement between the interpretations and diagnoses provided by the two readers was compared. Correlation with available additional radiological exams was performed to confirm diagnoses provided from bone scan interpretations.

\section{Statistical analysis}

Descriptive statistics were used to evaluate the findings and results. Inter-reader agreement upon diagnosis was tested using Fleiss' generalized Kappa test; a Kappa value of 1.0 indicates perfect agreement between readers, while a Kappa value of 0.0 indicates no agreement.

\section{Results}

A total of 35 consecutive patients met the criteria for inclusion in this study: 19 females and 16 males, with an average age of 44 years (range: 10-99 years). The most common indications for performing these studies were pain in lower back or pelvis (13 patients), the knees ( 9 patients), the lower legs ( 6 patients), and the feet in (7 patients). The two readers made diagnoses for the etiology of the complaint, based on the findings seen on the bone scan, as outlined in Table 1. There was agreement between the two readers on the site of pathology in 32 out of 35 patients. There was also good inter-reader agreement about the etiology of the abnormalities or lesions, with a Kappa value of 0.88 . The degree of certainty for both readers increased significantly with the addition of SPECT-CT, as shown in Table 2. The certainty of diagnosis increased $26 \%$ for reader 1 , from using planar images alone, to $44 \%$, with the addition of SPECT, to $74 \%$, with the addition of SPECT-CT, and from $40 \%$, to $54 \%$, to $69 \%$, respectively, for reader 2 (Figure 1). SPECT alone added six (17\%) new sites of pathology to those identified through planar images, changed the diagnosis for one patient from shin splint to stress fracture (Figure 2), and added a diagnosis of tendinitis for one $(6 \%)$ other patient. SPECT-CT changed the diagnosis for three patients, and added a new diagnosis (11\%) for one patient. The diagnoses changed were post-surgical uptake around screws or pins, instead of arthritis, in two patients, and enchondroma (Figure 3), instead of a metastasis, in one patient. SPECT-CT also added a diagnosis of compression fracture for a fourth patient. Only two patients interpreted by reader 1 and one patient interpreted by reader 2 had an NC diagnosis, even after the addition of SPECT-CT. One of these patients had a follow-up CT scan that proved degenerative arthritis 
Table I Diagnoses of lower extremity abnormalities, as identified from bone scan with SPECT-CT, for each reader

\begin{tabular}{ll}
\hline No of patients & Diagnosis \\
\hline Reader I & \\
7 & Stress fractures \\
2 & Compression fracture \\
8 & Degenerative arthritis \\
3 & Metastasis \\
I & Spur \\
I & Heterotophic ossification \\
2 & Shin splints \\
I & Avascular necrosis \\
3 & Inflammation around hardware \\
I & Enchondroma \\
I & Uncertain \\
4 & Normal \\
I & Nonunion of a fracture \\
Reader 2 & \\
5 & Stress fractures \\
2 & Compression fracture \\
9 & Degenerative arthritis \\
3 & Metastasis \\
I & Spur \\
I & Heterotophic ossification \\
2 & Shin splints \\
3 & Avascular necrosis \\
2 & Inflammation around hardware \\
I & Neoplasm \\
5 & Osteomyelitis \\
\hline Abbreviation: SPECT-CT, single photon emission computed tomography-computed \\
tomography. & Normal \\
\hline
\end{tabular}
tomography.

around the acetabulum, and no metastasis. The second patient, who had a lesion that was graded $\mathrm{NC}$ by reader 1 , underwent biopsy that proved benign sclerosis and no metastasis.

Additional correlative radiologic imaging was available for 23 of the patients and one patient had a biopsy. Confirmation of the diagnosis made from bone scan with SPECT-CT was achieved in 18 out of 23 patients, when correlated with

Table 2 Number of patients in different diagnostic certainty categories using planar, planar with SPECT, and planar with SPECT-CT imaging

\begin{tabular}{llll}
\hline & $\begin{array}{l}\text { Planar } \\
\text { images }\end{array}$ & $\begin{array}{l}\text { Planar }+ \\
\text { SPECT }\end{array}$ & $\begin{array}{l}\text { Planar }+ \\
\text { SPECT-CT }\end{array}$ \\
\hline Reader I & & & \\
NC & 11 & 5 & 2 \\
SC & 15 & 14 & 7 \\
C & 9 & 16 & 26 \\
Reader 2 & & & \\
NC & 4 & 2 & 1 \\
SC & 17 & 14 & 10 \\
C & 14 & 19 & 24 \\
\hline
\end{tabular}

Abbreviations: NC, not certain of diagnosis; SC, somewhat certain of diagnosis; $\mathrm{C}$, certain of diagnosis.

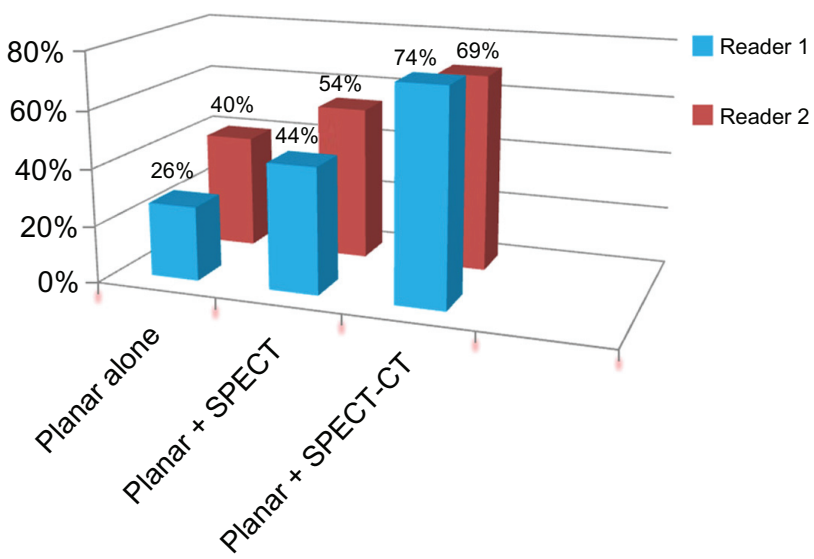

Figure I Increase in degree of diagnostic certainty with the addition of SPECT and SPECT-CT imaging.

Abbreviations: SPECT, single photon emission computed tomography; SPECT-CT, single photon emission computed tomography-computed tomography.

other imaging modalities. The remaining five patients were diagnosed with stress fractures, which are usually better detected using bone scan than with any other imaging modality. The patients responded to routine management of stress fractures, with relief of symptoms.

\section{Discussion}

The lower extremities are the site of many complaints and symptoms that are unexplained by conventional X-ray imaging. Magnetic resonance imaging (MRI) occasionally shows abnormalities that do not explain a patient's symptoms, or shows no abnormality at all. Bone scans are a sensitive imaging modality that can identify abnormalities at an early stage. Our results demonstrate the additional value of SPECT-CT imaging over planar bone scan with SPECT alone. The additional value of fused SPECT-CT images was demonstrated in the increased certainty of the reading physicians' diagnoses. There was an increase in certainty of diagnosis between planar and planar with SPECT-CT of approximately $48 \%$ for reader 1 . The increase in certainty of diagnosis for reader 2 was $29 \%$. There was also a high degree of agreement between the two readers' findings. Our results confirm those of other studies that have evaluated the usefulness of SPECT-CT for certain disease processes.

Utsunomiya et al, who evaluated the performance of fused SPECT-CT versus planar bone scan and side-by-side planar bone and CT scan, demonstrated that the highest area under the curve for receiver operating characteristics was from the fused SPECT-CT images, when evaluating 42 metastatic bony lesions and 40 benign lesions. ${ }^{19}$ Gayed et al evaluated the usefulness of SPECT-CT in characterization of solitary skull lesions as benign or malignant, and 
A

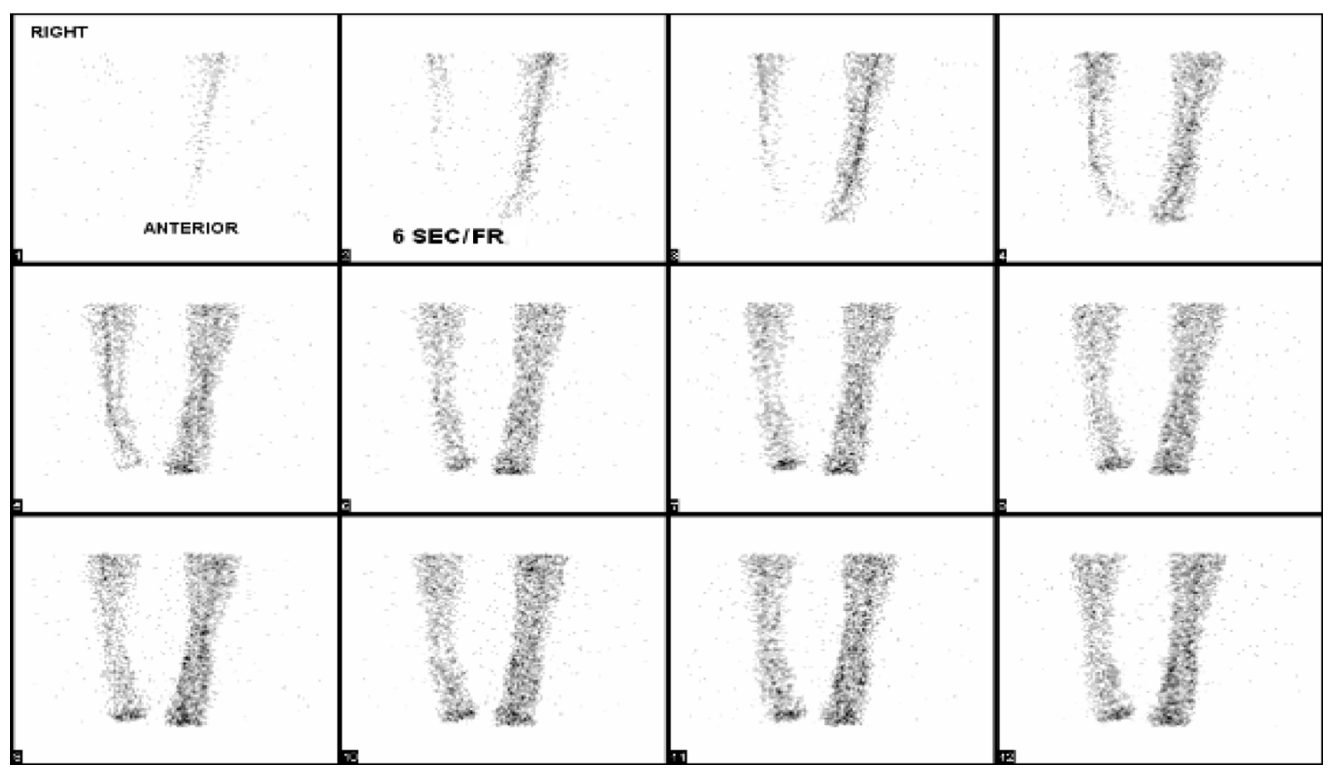

B

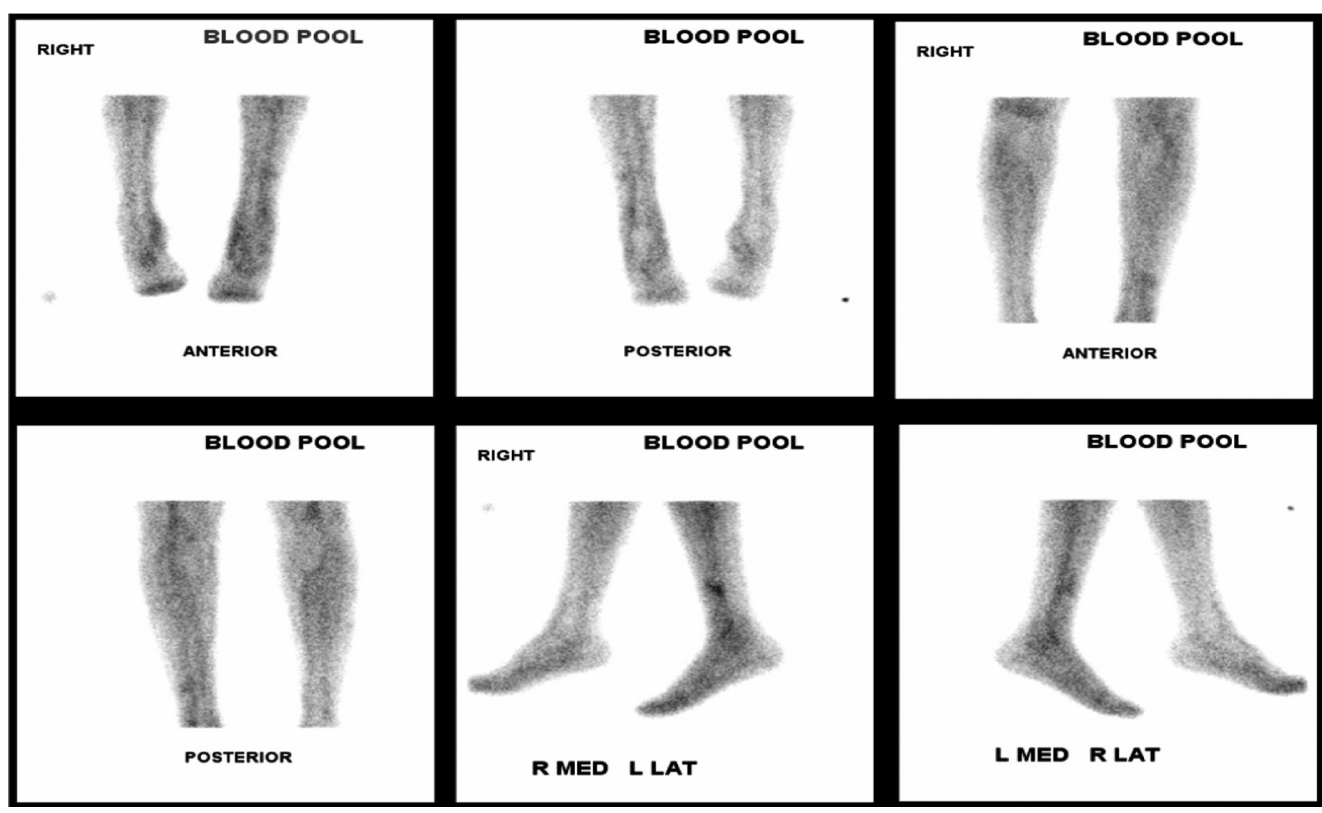

C

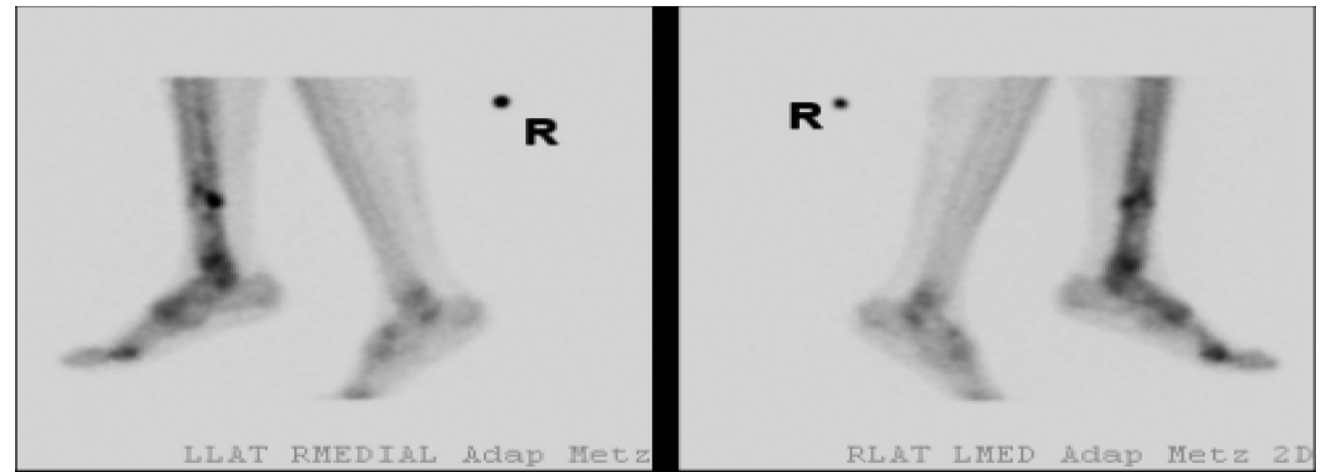

Figure 2 (Continued) 

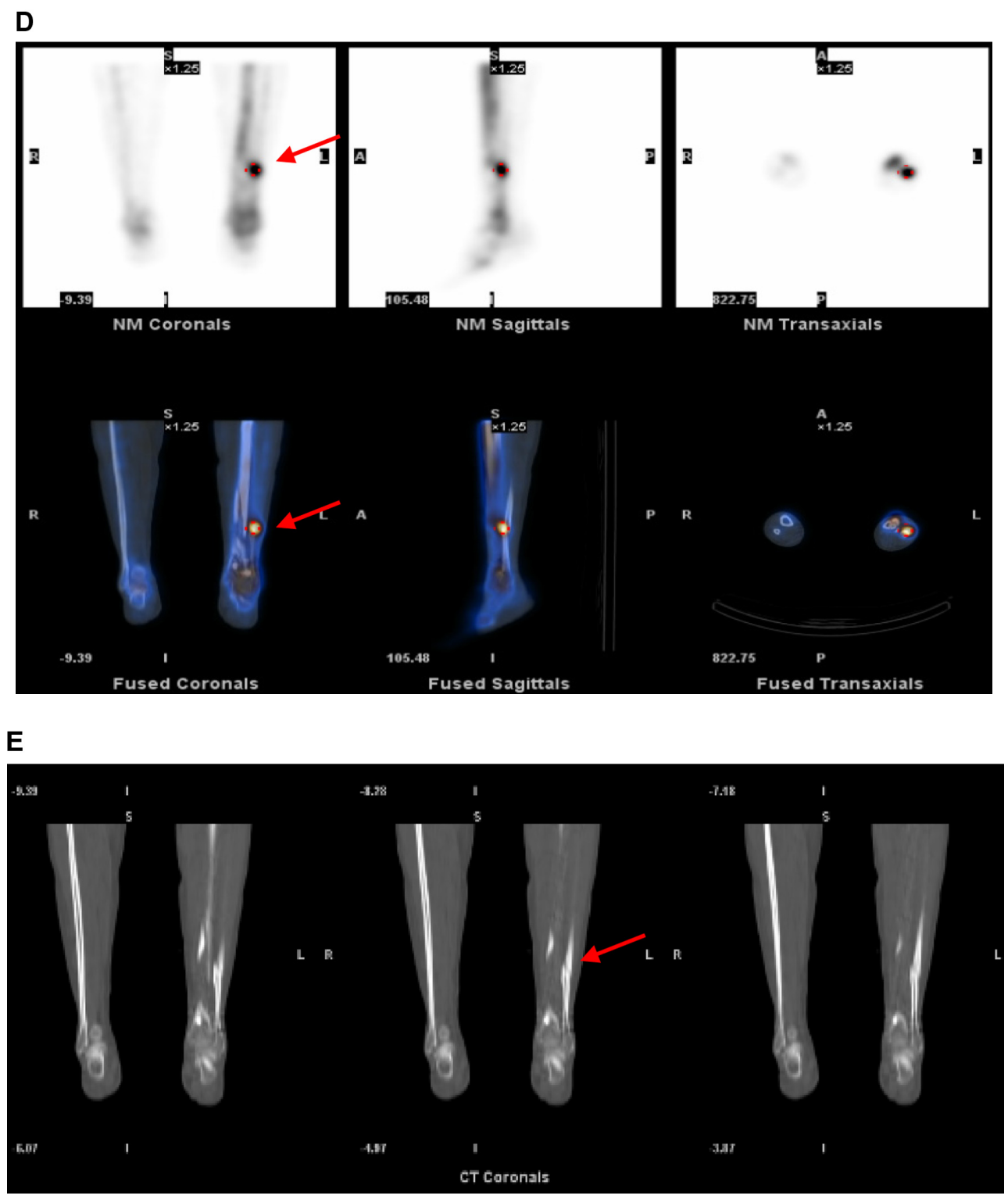

Figure 2 (A) blood flow, (B) blood pool, and (C) delayed images of a three-phase bone scan in a patient with left lower leg pain, demonstrating a lesion with increased tracer uptake in the left distal fibula. (D and E) SPECT-CT images confirm the presence of a fracture at this site, indicated by arrows.

Abbreviation: SPECT-CT, single photon emission computed tomography-computed tomography.

reported the sensitivity, specificity, positive, and negative predictive values of SPECT-CT images in identifying metastatic lesions at $100 \%, 92 \%, 75 \%$, and $100 \%$, respectively. ${ }^{20}$ An investigation by Filippi and Schillaci ${ }^{21}$ proved SPECT-CT to be useful in differentiating between soft tissue and prosthetic implant infections in 13 patients with surgically proven infection.

Römer et al evaluated the performance of SPECT-CT imaging for 52 lesions that were considered indeterminate on SPECT images alone. SPECT-CT correctly categorized $63 \%$ of these indeterminate lesions as benign, $29 \%$ as metastatic, and $8 \%$ indeterminate. ${ }^{22}$ Most of the lesions that remained indeterminate were in flat bones, such as the ribs and scapulae. In contrast, Strobel et al reported the sensitivity and specificity of SPECT-CT to be $100 \%$ and $100 \%$, respectively, when evaluating the etiology of axial bony lesions. ${ }^{23}$

The performance of side-by-side versus simultaneous SPECT-CT imaging is an area of debate. Horger et al found that the interpretation of separate SPECT and CT/ $\mathrm{X}$-Ray/MRI in identifying osteomyelitis is most sensitive $(100 \%)$, compared to fused SPECT-CT $(78 \%) .{ }^{24}$ On the other hand, Utsunomiya et al have shown that analysis of simultaneously fused SPECT-CT images was significantly superior to side-by-side viewing of two sets of images (SPECT and CT). ${ }^{19}$ In all senarios, the convenience of 
A

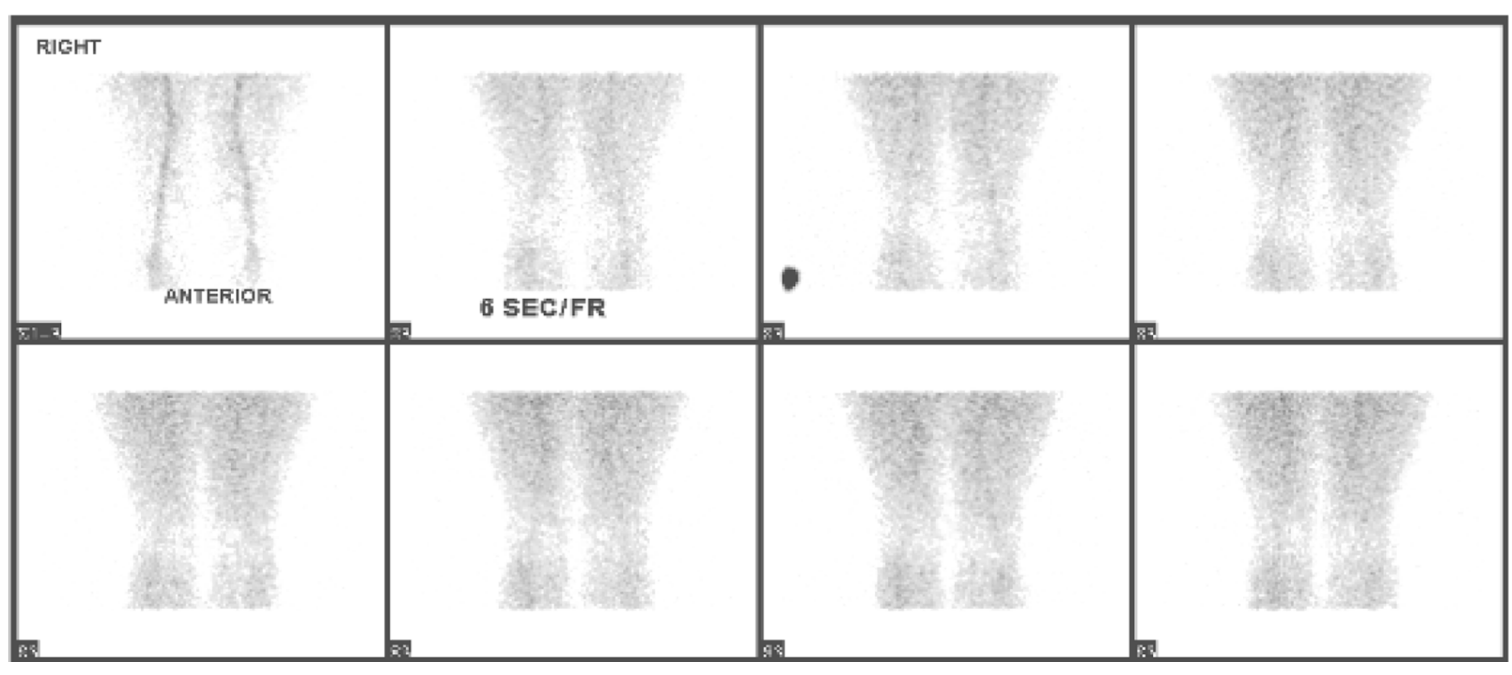

B

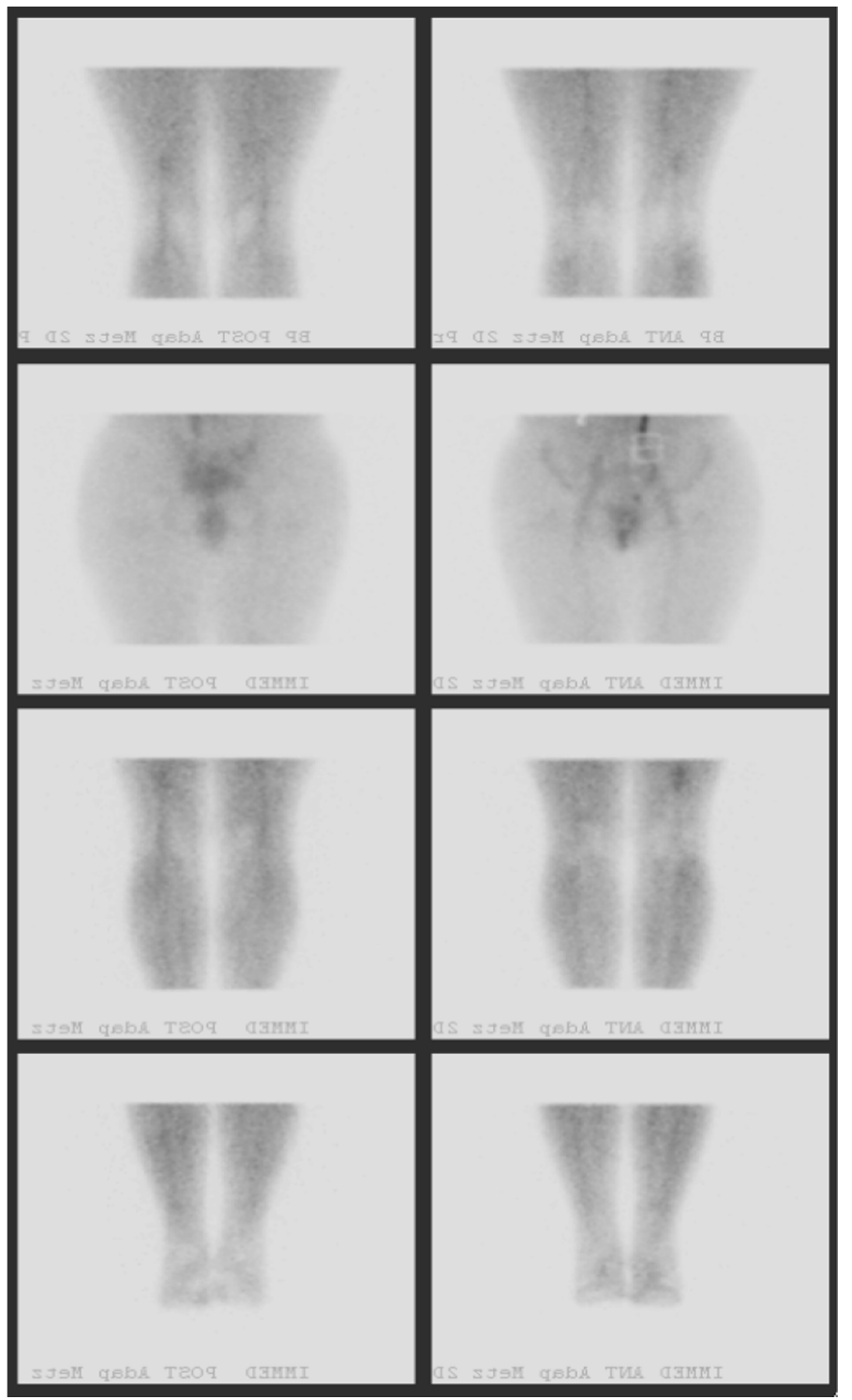

Figure 3 (Continued) 


\section{C}

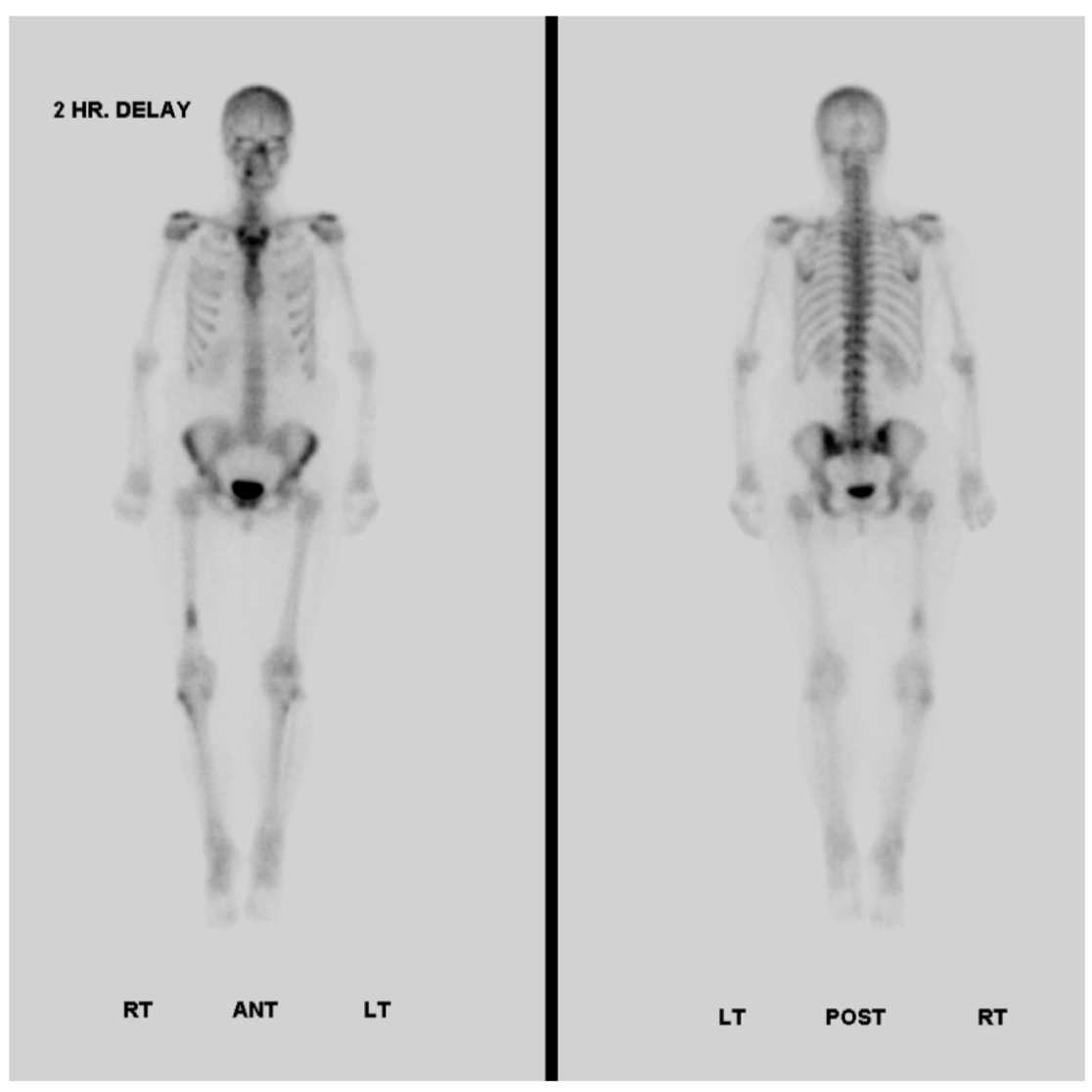

D

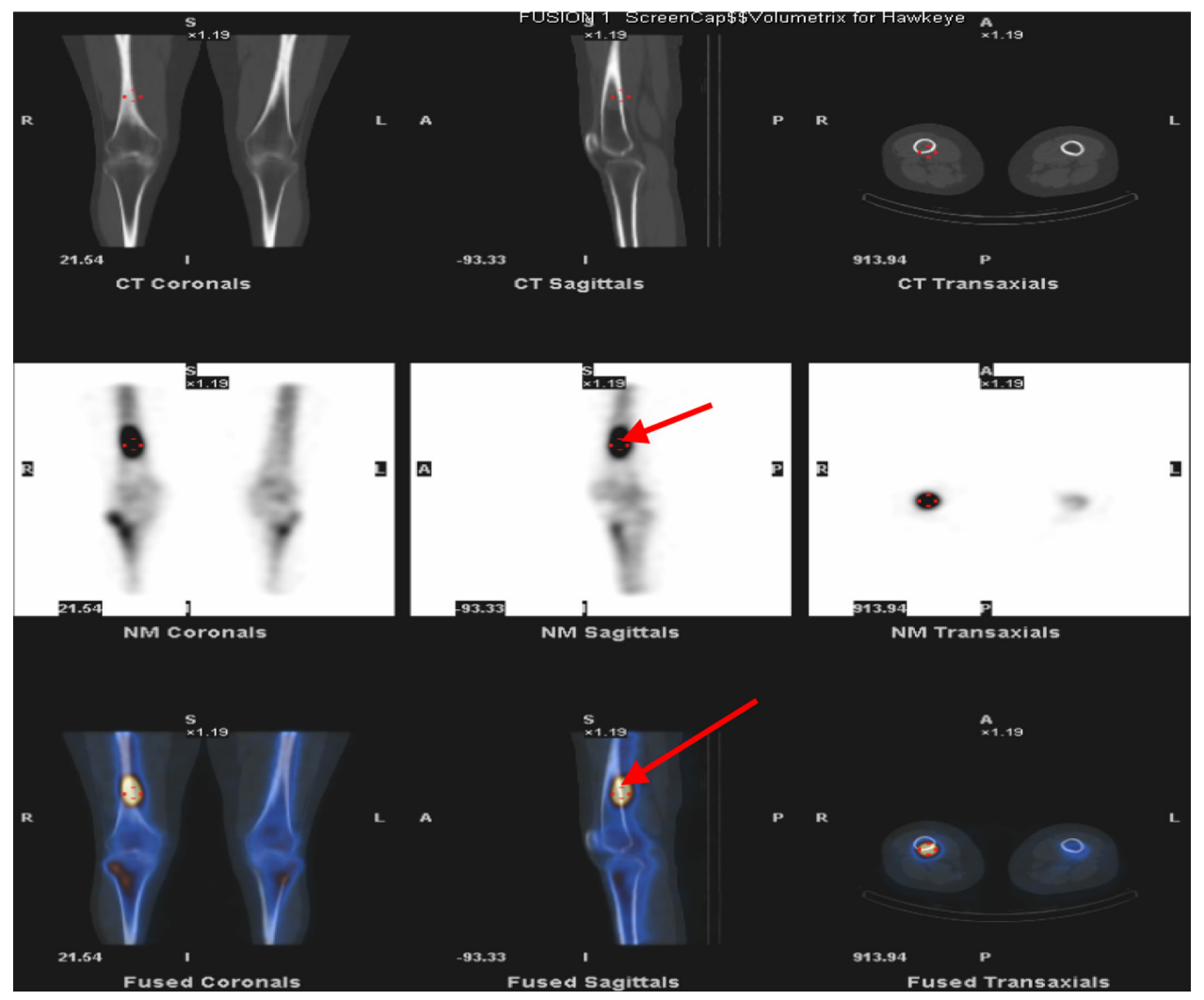

Figure 3 (Continued) 


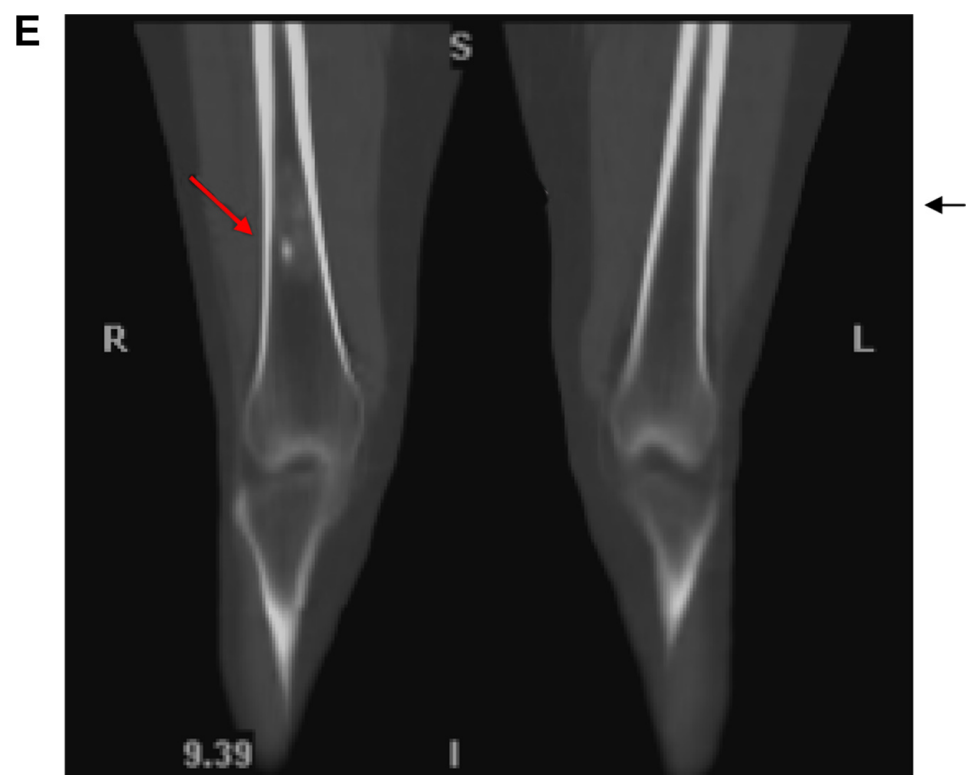

Figure 3 (A) blood flow, (B) blood pool, and (C) delayed whole-body images of a three-phase bone scan, with (D and E) SPECT-CT images, demonstrating a lesion confined to the medulla of the right distal femur, indicated by arrows.

Notes: The images suggested a lesion and excluded malignant etiology. This was confirmed on follow-up exam.

Abbreviation: SPECT-CT, single photon emission computed tomography-computed tomography.

reaching a diagnosis from one procedure, with significant time and cost reduction, is a clear advantage of simultaneous SPECT-CT imaging. ${ }^{25}$

Our study also showed that SPECT alone added six (17\%) new sites of pathology to those identified through planar imaging alone, changed the diagnosis in one patient, and added a diagnosis (6\%) in another. This is attributed to the established superior contrast and localization capabilities of SPECT over planar imaging. Additionally, SPECT-CT changed the diagnosis in three patients and added another diagnosis $(11 \%)$ in one patient.

These revisions of diagnoses are due mainly to SPECT-CT's superior spatial resolution and localization for adjacent lesions. This has previously been demonstrated in the ability of SPECT-CT to identify more lymph nodes, and to separate adjacent sentinel lymph nodes, when used for sentinel lymph node mapping with lymphoscintigraphy. ${ }^{26-28}$

A limitation of our study is the lack of confirmation of the etiology of lesions in all patients, due to the retrospective nature of the study. However, the high degree of agreement between the two readers upon the location and etiology of the abnormalities is supportive of accurate interpretation of the bone scans.

\section{Conclusion}

SPECT-CT increased the certainty of location and diagnosis of bony pathology in the lower extremity by at least $30 \%$. It can find additional lesions, not seen on planar images, which can change the diagnosis or add additional diagnoses for different lesions.

\section{Disclosures}

None of the authors had any financial interest or benefit from this study. There are no conflicts of interest to be disclosed by any of the authors.

\section{References}

1. Song JW, Oh YM, Shim TS, et al. Efficacy comparison between (18) F-FDG PET/CT and bone scintigraphy in detecting bony metastases of non-small-cell lung cancer. Lung Cancer. 2009;65(3):333-338.

2. McNeil BJ. Value of bone scanning in neoplastic disease. Semin Nucl Med. 1984;14(4):277-286.

3. Hach A, Hahn K. The value of nuclear medicine for the diagnosis of spine diseases. Neurosurg Rev. 1993;16(2):125-133.

4. Ahmed A, Glynne-Jones R, Ell PJ. Skeletal scintigraphy in carcinoma of the breast - a ten year retrospective study of 389 patients. Nucl Med Commun. 1990;11(6):421-426.

5. Brown ML. Bone scintigraphy in benign and malignant tumors. Radiol Clin North Am. 1993;31(4):731-738.

6. Ohta M, Tokuda Y, SuzukiY, et al. Whole body PET for the evaluation of bony metastases in patients with breast cancer: comparison with $99 \mathrm{Tcm}-$ MDP bone scintigraphy. Nucl Med Commun. 2001;22(8):875-879.

7. Merrick MV, Beales JS, Garvie N, et al. Evaluation and skeletal metastases. Br J Radiol. 1992;65(777):803-806.

8. Aitchison FA, Poon FW, Hadley MD, et al. Vertebral metastases and an equivocal bone scan: value of magnetic resonance imaging. $\mathrm{Nucl}$ Med Commun. 1992;13(6):429-431.

9. Evans AJ, Robertson JF. Magnetic resonance imaging versus radionuclide scintigraphy for screening in bone metastases. Clin Radiol. 2000;55(8):653-654.

10. Gosfield E 3rd, Alavi A, Kneeland B. Comparison of radionuclide bone scans and magnetic resonance imaging in detecting spinal metastases. J Nucl Med. 1993;34(12):2191-2198. 
11. Bellamy EA, Nicholas D, Ward M, et al. Comparison of computed tomography and conventional radiology in the assessment of treatment response of lytic bony metastases in patients with carcinoma of the breast. Clin Radiol. 1987;38(4):351-355.

12. Libshitz HI, Hortobagyi GN. Radiographic evaluation of therapeutic response in bony metastases of breast cancer. Skeletal Radiol. 1981;7(3):159-165.

13. Kato H, Miyazaki T, Nakajima M, et al. Comparison between whole-body positron emission tomography and bone scintigraphy in evaluating bony metastases of esophageal carcinomas. Anticancer Res. 2005;25(6C):4439-4444.

14. Helyar V, Mohan HK, Barwick T, et al. The added value of multislice SPECT/CT in patients with equivocal bony metastasis from carcinoma of the prostate. Eur J Nucl Med Mol Imaging. 2010;37(4):706-713.

15. Hirschmann MT, Iranpour F, Konala P, et al. A novel standardized algorithm for evaluating patients with painful total knee arthroplasty using combined single photon emission tomography and conventional computerized tomography. Knee Surg Sports Traumatol Arthrosc. 2010;18(7):939-944.

16. Kobayashi K, Ramirez PT, Kim EE, et al. Sentinel node mapping in vulvovaginal melanoma using SPECT/CT lymphoscintigraphy. Clin Nucl Med. 2009;34(12):859-861.

17. Gayed IW, Chang J, Kim EE, et al. Lung perfusion imaging can risk stratify lung cancer patients for the development of pulmonary complications after chemoradiation. J Thorac Oncol. 2008;3(8): 858-864.

18. Perrier ND, Edeiken B, Nunez R, et al. A novel nomenclature to classify parathyroid adenomas. World J Surg. 2009;33(3):412-416.

19. Utsunomiya D, Shiraishi S, Imuta M, et al. Added value of SPECT/ CT fusion in assessing suspected bone metastasis: comparison with scintigraphy alone and nonfused scintigraphy and CT. Radiology. 2006;238(1):264-271.
20. Gayed I, Kim EE, Awad J, et al. The value of fused single photon emission computed tomography (SPECT) with computed tomography (CT) in the evaluation of solitary skull lesion. Clin Nucl Med. 2011;36(7):538-541.

21. Filippi L, Schillaci O. Usefulness of hybrid SPECT/CT in 99mTcHMPAO-labeled leukocyte scintigraphy for bone and joint infections. J Nucl Med. 2006;47(12):1908-1913.

22. Römer W, Nömayr A, Uder M, et al. SPECT-guided CT for evaluating foci of increased bone metabolism classified as indeterminate on SPECT in cancer patients. $J$ Nucl Med. 2006;47(7):1102-1106. Erratum in: J Nucl Med. 2006;47(10):1586.

23. Strobel K, Burger C, Seifert B, et al. Characterization of focal bone lesions in the axial skeleton: performance of planar bone scintigraphy compared with SPECT and SPECT fused with CT. AJR Am J Roentgenol. 2007;188(5):W467-W474.

24. Horger M, Eschmann SM, Pfannenberg C, et al. Added value of SPECT/CT in patients suspected of having bone infection: preliminary results. Arch Orthop Trauma Surg. 2007;127(3):211-221.

25. Bockisch A, Freudenberg LS, Schmidt D, et al. Hybrid imaging by SPECT/CT and PET/CT: proven outcomes in cancer imaging. Semin Nucl Med. 2009;39(4):276-289.

26. Bilde A, Von Buchwald C, Mortensen J, et al. The role of SPECT-CT in the lymphoscintigraphic identification of sentinel nodes in patients with oral cancer. Acta Otolaryngol. 2006;126(10):1096-1103.

27. Khafif A, Schneebaum S, Fliss DM, et al. Lymphoscintigraphy for sentinel node mapping using a hybrid single photon emission CT (SPECT)/CT system in oral cavity squamous cell carcinoma. Head Neck. 2006;28(10):874-879.

28. Husarik DB, Steinert HC. Single-photon emission computed tomography/computed tomography for sentinel node mapping in breast cancer. Semin Nucl Med. 2007;37(1):29-33.
Research and Reports in Nuclear Medicine

\section{Publish your work in this journal}

Research and Reports in Nuclear Medicine is an international, peerreviewed, open access journal publishing original research, reports, reviews and commentaries on all areas of nuclear medicine. The manuscript management system is completely online and includes a very

\section{Dovepress}

quick and fair peer-review system. Visit http://www.dovepress.com/ testimonials.php to read real quotes from published authors. 